\title{
Miniaturised Asymmetrical E-Shaped Patch Antenna With Circular Polarisation
}

\author{
Ishleen kaur \\ Department of Electronics and Communication Engineering \\ GTBIT, New Delhi,India
}

\begin{abstract}
Abstract should be times This paper includes the simulation and design parameter microstrip E-shaped patch antenna, demonstrating different operating frequencies. In this study three unequal resonance arms are fed by probe feed to the folded patch in order to increase the impedance bandwidth. The miniaturisation of the size of patch is done by the application of shorting pins . The performance of broadening the impedance bandwidth is explored by investigating the behavior of surface currents in patch. The tuning resonance ability of antenna is present within the impedance bandwidth by varying the length of unequal resonance arms. For ultra-wideband applications the measured $-10 \mathrm{~dB}$ impedance bandwidth of fabricated antenna is $76.18 \%$ from 3.34 to $7.45 \mathrm{GHz}$. The size of the antenna is $0.379 \lambda_{\mathrm{L}} \times 0.145 \lambda_{\mathrm{L}}$ $\times 0.078 \lambda_{\mathrm{L}}$, where $\lambda_{\mathrm{L}}$ is wavelength at the lower frequency of measured operating bandwidth in the free space. It is designed by air substrate which has a dielectric constant of 1.0006. In addition to this, parametric studies are done by investigating the effect of different key parameters on obtaining an optimal design of the proposed antenna design.
\end{abstract}

Keywords - Patch Antenna, E-Shaped Antenna, Co-axial feed Antenna.

\section{INTRODUCTION}

In Wireless communication and in Global Positioning system Microstrip patch antenna is key building technique since it was first demonstrated in 1986 by Heinrich Hertz and its practical application by Gulielmo Marconi in 1901.Microstrip antenna has a great consideration because of its light Weight,Low profile,Compatibility integration and with other circuits and subsystems, low cost and immunity to multipath interference. Those Microstrip antennas which are having Narrow Impedance Bandwidth various methods have been accomplished to overcome this problem in order to achieve ultra-wideband (UWB) performance. The frequency range of the UWB wireless standard has been allocated from 3.1 to $10.6 \mathrm{GHz}[1]$. Nowadays a compact Wideband antenna is exclusively accentuated in commercial and military systems. It operates in C-band and partially in S-band which makes it suitable for UWB applications such as Wireless monitoring and home networking.

When the size of the microstrip antenna is reduced then the bandwidth impedance gets reduced. Many techniques have been used to miniaturized the size of the antenna such as meandered patch[2], shorting pin/wall[3-5] , by applying the shorting pin loading technique at microstrip antenna exhibits a quarter-wavelength structure. Also there are several more techniques used to enhance the impedance bandwidth for example: by utilising a thick substrate [6], modification in patch geometric structure like E-shaped patches[7-8] , U-shaped-slot patch[9] . Other useful techniques to improve the impeadance bandwidth are implementation of stacked patch antenna[10], L-probe feed[11], shorted patch[12], shorting pins[13]. In earlier investigations , an E-shaped patch antenna fed by a folded L-shaped probe with unequal arms provides an impedance bandwidth of 19.8\% [14]. In asymmetric patch dimensions of $25 \times 27.7 \mathrm{~mm}^{2}$, which has been mounted above the ground plane with dimensions of $62.5 \times 100 \mathrm{~mm}^{2}$, produces three adjacent resonances to achieve a wideband antenna. Also, modified E-shaped patch antennas with unequal resonance arms for producing different resonances have been introduced in $[15,16]$. In [16] usage of shorting walls is utilized on asymmetric arms inorder to enhance impedance bandwidth. Recently by introducing the novel feeding method namely folded- patch feed, the impedance bandwidth of patch antenna has been improved[17,18]. An E-shaped patch antenna with folded patch feed is introduced to have an impedance bandwidth of $73.78 \%$ [19].

In this article, a probe- fed microstrip patch antenna with an asymmetric rectangular patch based on unequal resonance arms and a folded patch feed to broaden the bandwidth is introduced. It includes impedance badwidth ranging from 3.34to $7.45 \mathrm{GHz}$ for UWB applications. Moreover, two shorting pins are applied in the proposed structure to reduce the size of antenna. Also, the radiation pattern acceptable stability over the frequency band acquired in both E- and H- planes. 
with a parametric study is used to attain an optimal broadband performance when shorting pins of various diameters at different positions were incorporated. According to the geometric structure of proposed antenna in Fig.1, the optimised diameters of the two pins are $1.4 \mathrm{~mm}$ for providing the optimum impedance bandwidth. It should be mentioned that the shorting pins make the antenna resonates at a lower frequency compared with antenna without them . Thus, the antenna with an acceptable miniaturization can be achieved.

The asymmetric E-shaped patch with dimensions of $34 \times 13 \mathrm{~mm}^{2}$ is located at height $h_{2}$ from the ground plane .In achieving a wideband width the slot length, width and position plays an significant roles. The asymmetric E shaped patch produces three resonances, with incorporation of two parallel slots into the upper patch and unequal resonance arms. The width of the slot that's between $\mathbf{w}_{7}$ and $\mathbf{w}_{\mathbf{8}}$ is $1 \mathrm{~mm}$ and the length of that slot is $10 \mathrm{~mm}$. Therefore, the wider bandwidth can be achieved. The main advantage of the proposed antenna is its ability in tuning the resonances and the variation of slot's length and arms's length affect tuning of three resonances. By adjusting the longer, middle and shorter arms on upper patch can principally control the first, second and third resonances, respectively, in order to widen the impedance bandwidth of the antenna significantly. As compared with the antennas reported in $[17,18]$ the proposed antenna has a wider bandwidth. This antenna can be made from the single piece of copper plate without the need of soldering the folded part to upper patch .The other advantage of the antenna is that it is simpler and easier fabrication process compared with the similar antennas such as Ushaped -slot and L-shaped slit patch with folded-patch feed technique. The optimum design values are determined with the parametric studies to find out the overall dimensions, slots and arms length. In addition, to choose the proper dimension for an optimal design, the minimum ripples of the gain with in the impedance bandwidth are considered. Several key parameters that help to achieve an optimal design are described in section 4. The dimensions of proposed antenna are given in Table1.

\subsection{Tables}

Table - 1 Dimensions of proposed antenna (units in $\mathrm{mm}$ )

\begin{tabular}{|c|c|}
\hline Parameters & Values \\
\hline $\mathbf{W}$ & 34 \\
\hline$W_{1}$ & 6 \\
\hline $\mathbf{W}_{2}$ & 6 \\
\hline $\mathbf{W}_{3}$ & 10 \\
\hline$W_{4}$ & 6 \\
\hline $\mathbf{W}_{5}$ & 6 \\
\hline$W_{6}$ & 23 \\
\hline $\mathbf{W}_{7}$ & 4 \\
\hline $\mathbf{W}_{8}$ & 5 \\
\hline $\mathbf{L}$ & 13 \\
\hline $\mathbf{L}_{1}$ & 9 \\
\hline $\mathbf{L}_{2}$ & 7 \\
\hline $\mathbf{L}_{3}$ & 5 \\
\hline $\mathbf{L}_{4}$ & 5 \\
\hline $\mathbf{L}_{\mathbf{G}}$ & 60 \\
\hline $\mathbf{L}_{\mathrm{s}}$ & 9 \\
\hline $\mathbf{L}_{\mathbf{m}}$ & 11 \\
\hline $\mathbf{h}_{1}$ & 3.4 \\
\hline $\mathbf{h}_{2}$ & 7 \\
\hline $\mathbf{W}_{\mathbf{G}}$ & 60 \\
\hline $\mathbf{S}$ & 1.5 \\
\hline $\mathbf{F}$ & 3 \\
\hline Feed point & $(-0.5,4.5)$ \\
\hline
\end{tabular}

\subsection{Simulation and measurements results}

Anasoft version 12 High Frequency Structure Simulator Software (HFSS) is used for prediction and optimization of antenna's resonant properties. The design procedure begins with determining the length, width and the of dielectric substance for the given operating frequency . As shown in the Fig.2, the proposed antenna operates from 
3.34 to $7.45 \mathrm{GHz}$ and measured $-10 \mathrm{~dB}$ impedance bandwidth is $76.18 \%$. The measured results are in agreements with the simulation results obtained using a finite ground plane. The proposed antenna has an enhancement of $20 \%$ in impedance compared with antenna reported in [17]. The 10\% enhancement of bandwidth has also obtained when the slot has been cut in the middle of the arms of folded E-patch antenna. The impedance Anasoft version 12 High Frequency Structure Simulator Software (HFSS) is used for prediction bandwidth of antenna is more than triple of that of the E-shaped patch antenna with unequal resonance arms in [14]. The length, width and total height of patch in terms of wavelength at the lower end of frequency band are $0.379_{\mathrm{L}}, 0.145 \lambda_{\mathrm{L}}$ and $0.078 \lambda_{\mathrm{L}}$, respectively whereas the length of probe is $0.038 \lambda_{\mathrm{L}}$. In comparison with a conventional patch antenna, $78.1 \%$ size reduction is achieved by the proposed structure. Also, to highlight the proposed antenna, in comparison with the conventional E-shaped patch antenna which is reported in [7]. In [17], an impedance bandwidth is $32.3 \%$ in the frequency range of 2.05$2.84 \mathrm{GHz}$ is obtained with an antenna size of $70 \times 45 \times 10 \mathrm{~mm}^{3}$. Thus our design result in $43.88 \%$ increases in the frequency bandwidth and $36.93 \%$ size reduction.

As per the stimulated gain of proposed antenna in Fig.3, at $7.45 \mathrm{GHz}$ the maximum broadside gain of the antenna within the bandwidth is $8.25 \mathrm{~dB}$. The measured and stimulated radiation pattern in the $\mathrm{xz}$-plane ( E-plane) and yzplane (H-plane) are shown in Fig.4. It has been observed that agreement between the measured and stimulated results are good. The measured and the stimulated radiation patterns in three frequencies within the bandwidth are approximately stable.

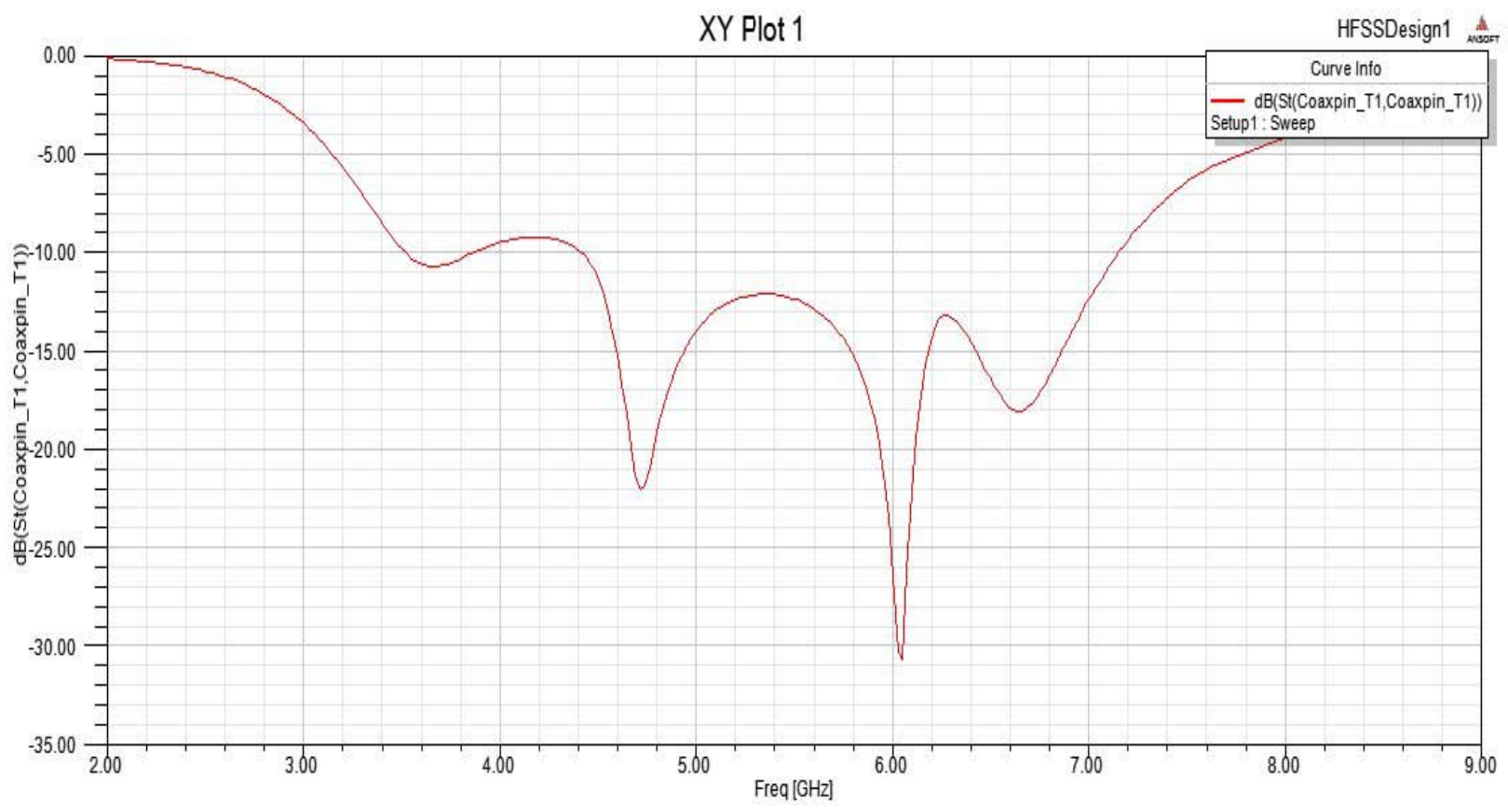

Figure2. Stimulated reflection coefficients of antenna

Also, the radiation patterns are not exactly symmetrical for electric fields in both planes because of its asymmetric structure. On the other hand, the antenna presents good broadside radiation patterns. At the same time, the crosspolarisation radiation is seems to be higher in the E-plane than that of in the H-plane. This is done because of the discontinuity in the structure obtained using the shorting pins and the feed location on the Y-axis. By the introduction of probe feed and shorting pins the asymmetry of the structure can effect on the increase of the contribution of the cross/-polarised radiation. The photograph of fabricated antenna is shown in Fig.11. In Fig.5. surface

current distribution on the patch at three frequencies are shown. It is clear that at the first resonance of $4.74 \mathrm{GHz}$, a typical $\lambda / 4$ patch antenna is exhibited. The current distribution along y-axis is non-uniform, which is observed with concentration around the slot between the longer arm and middle arm, as shown in Fig.5a. this is due to the asymmetry of the antenna. So, it is concluded that the first resonance corresponds to the longer arm. The second resonance is at $6.13 \mathrm{GHz}$, where a $\lambda / 2$ resonant antenna is exhibited. The concentration of current is around the slots of the asymmetric E-shaped patch antenna and on the edges of the folded part, as shown in Fig.5b. So, we can say 
that the second resonance corresponds to the middle arm. Likewise, the third resonance of $6.73 \mathrm{GHz}$, a $\lambda / 2$ resonant antenna is exhibited. As shown in Fig.5c, the distribution of current concentrates on the overall of the folded part specifically on its edges and the area upper the patch which connects to the folded part.

\subsection{Discussions on key parameters}

In this section, the effects of some key parameters are describe to investigate the performance of the antenna. Fig.6. demonstrate the variation of the probe length $\left(h_{1}\right)$. It has been observe that as a length $h_{1}$ increases, the feed of probe inductance increases, impedance matching deteriorates and consequently the impedance bandwidth decreases. The capacitive effect dominate, when the probe length reduces from an optimised value, which results in worse impedance bandwidth. The antenna's optimum value oh $h_{1}$ is $3.4 \mathrm{~mm}$. Moreover, the optimised value of $h_{2}$ is $7 \mathrm{~mm}$ for broadening the impedance bandwidth.

The first resonance frequency is mainly determined by length $L$ of the upper patch, as shown in Fig.5a.As seen from Figs $5 a$ and $b$, it is found that the length of slot $L_{1}$ affects the first and second resonances decrease and due to the fact that the current paths at these frequencies increase.

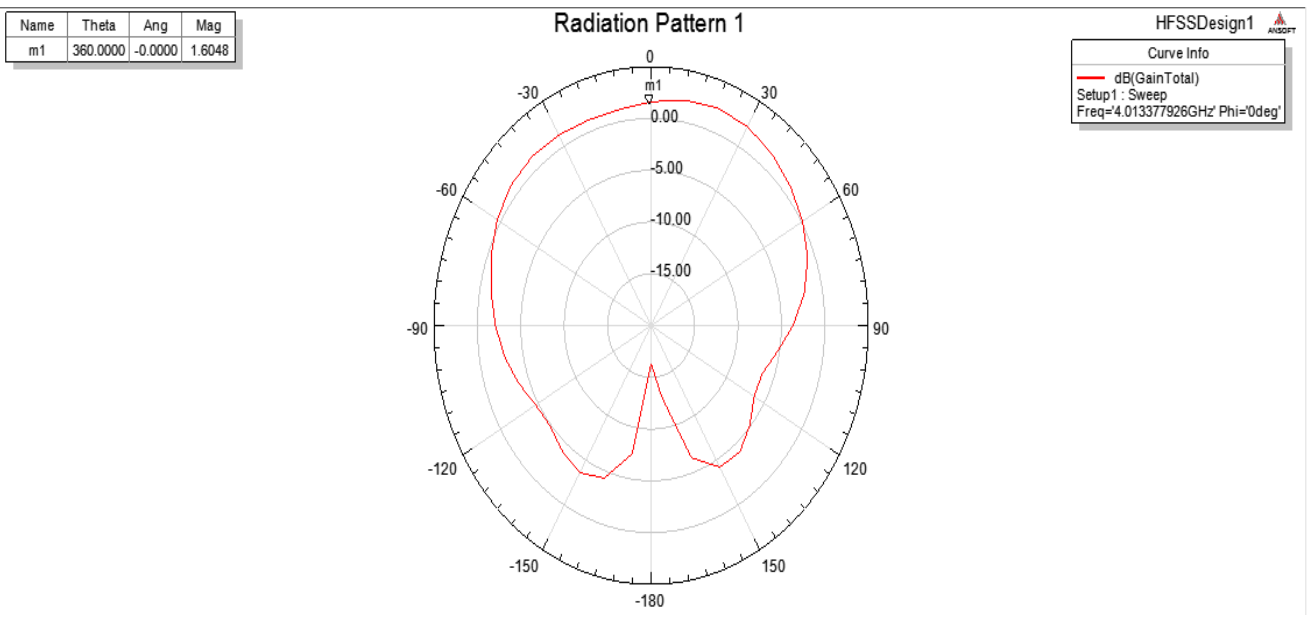

Figure3. Stimulated gain of antenna

Likewise, according to the Fig.8, when the slot length $\mathrm{L}_{3}$ increases, the second resonance decreases, because the current paths increase. Furthermore, the variations of $\mathrm{L}_{3}$ have a little effect on the third resonance. Optimum values of values of $\mathrm{L}_{1}=9 \mathrm{~mm}$ and $\mathrm{L}_{3}=5 \mathrm{~mm}$ are chosen for the optimal proposed antenna design. 


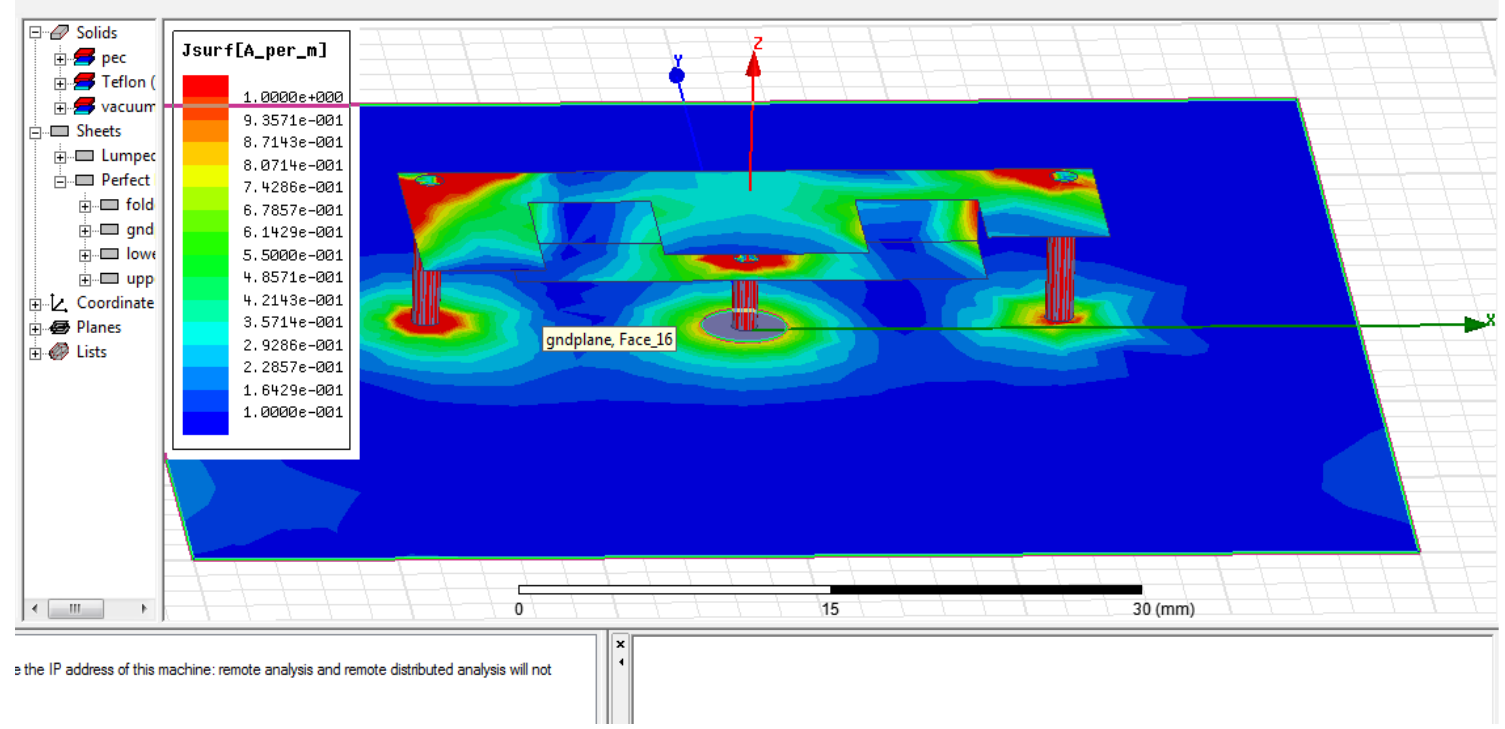

Figure4. Current distribution of the proposed antenna at different frequencies

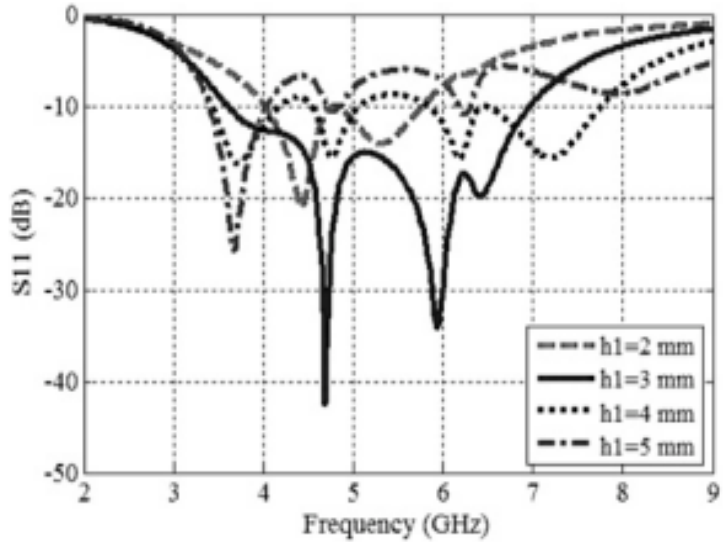

Figure 6 Simulated reflection coefficients for different Lengths for coaxial probe feed

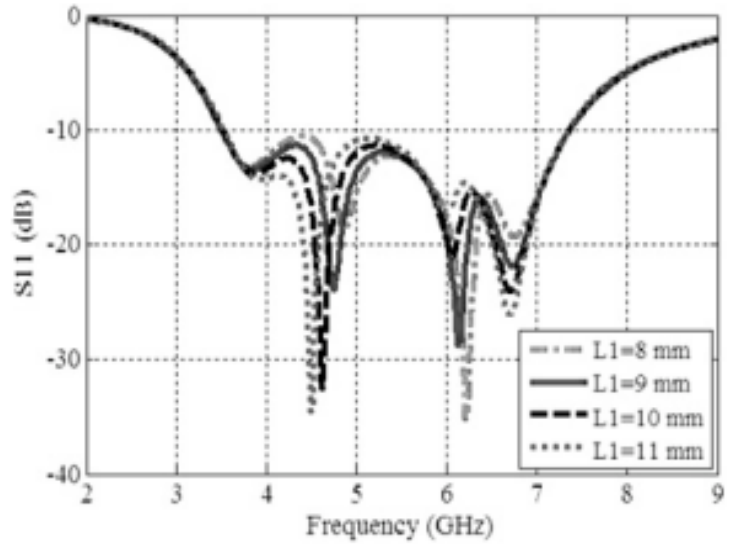

Fig.7. Reflection coefficients for different values of slot length $\mathrm{L}_{1}$ 


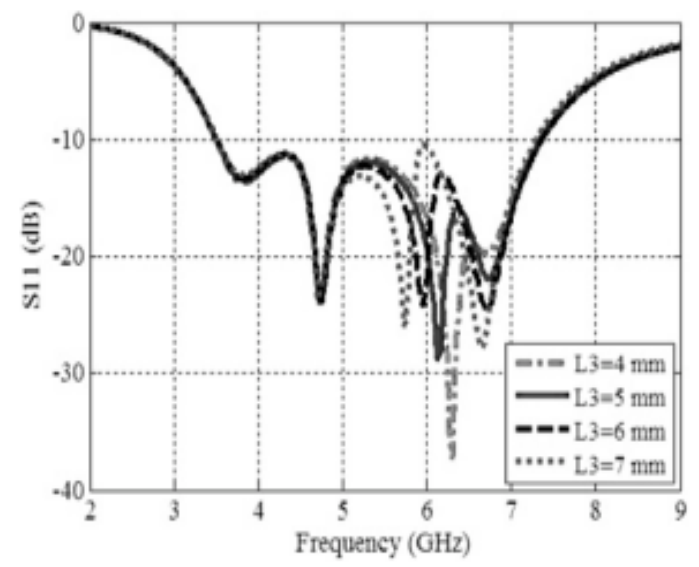

Figure 8 Reflection coefficients for different values length $\mathrm{L}_{3}$

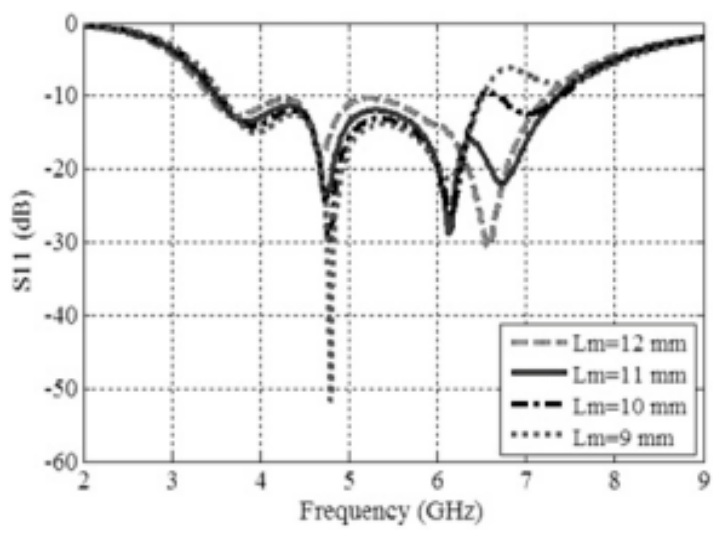

Figure 9 Reflection coefficients for different values of middle arm length $\mathrm{L}_{\mathrm{m}}$

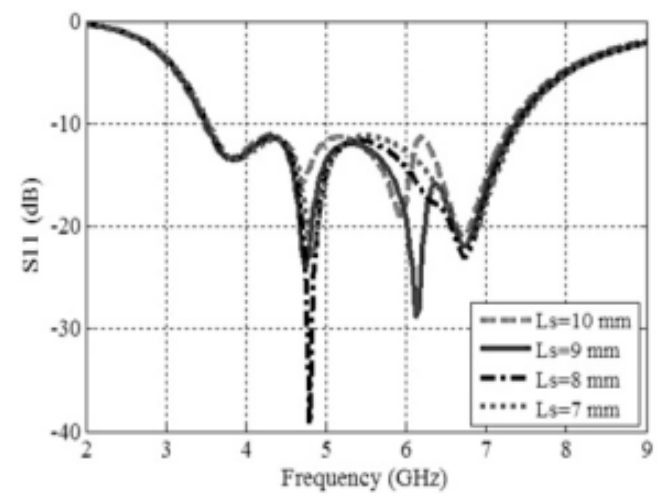

Figure 10 Reflection coefficient for different values of shorter arm length $L_{s}$

By the length of middle arm, $\mathrm{L}_{\mathrm{m}}$, of the upper patch the second resonance frequency can be mainly determined. As shown in the Fig.9. with an increase in $\mathrm{L}_{\mathrm{m}}$, the first and third resonance decreases, because the current paths prolong at these frequencies . In Fig. 10. the variations of the shorter arm $\mathrm{L}_{\mathrm{s}}$ of the upper patch are shown. With an increase in $L_{s}$, as the current paths at these frequencies increase, the first and second resonances mainly decrease. Therefore, it is concluded that the third resonance is mainly determined by $\mathrm{L}_{\mathrm{s}}$. The optimum values for length of the middle and shoreter arms are 11 and $9 \mathrm{~mm}$, respectively to achieve the optimal broadband operations.

\begin{tabular}{|l|c|c|}
\hline ANTENNA DESIGN & BANDWIDTH & POLARIZATION \\
\hline Square patch Antenna & $32.5 \%$ & Linear polarized \\
\hline E Shaped patch Antenna & $76.18 \%$ & Linear polarized \\
\hline E Shaped folded patch Antenna & $\mathbf{8 6 . 1 8 \%}$ & Circularly polarized \\
\hline
\end{tabular}


The modified E shaped folded patch antenna has an improvement in the bandwidth by $10 \%$ then the proposed antenna and $86.18 \%$ then the square patch antenna and CP is also achieved for the modified antenna with a axial ratio bandwidth of $2.2 \mathrm{GHz}$ and size of the antenna is reduced by $5 \%$ then the ESPA

\section{IV.CONCLUSION}

In this paper, a microstrip patch antenna with folded patch feed for UWB applications is designed, fabricated and tested to achieve bandwidth of $86.18 \%$ in $3.34-7.45 \mathrm{GHz}$. It consists of an asymmetric E-shaped patch fed by folded patch, which exictes three resonances for broadening the impedance bandwidth. Moreover, two shorting pins are used to reduced the size of an antenna. Impedance bandwidth performance are investigated through examining the behavior of the surface currents on the patch at three resonances. It is observed that the radiation patterns of the proposed antenna are nearly stationary within the bandwidth. An acceptable agreements is obtained with in the measured and simulated results. The effects of different key parameters are investigated to obtain optimised values of the proposed antenna.

\section{REFERENCES}

[1] wei. L.-A: 'Applications of ultra wideband' . (MS thesis. The university of Taxes at Arlington .2006

[2] Wong. K..L. Tang. C.L.. Chen. H.T.: 'A compact meandered circular microstrip antenna with a shorting pins'. Microw . Opt. Technol. Lett., 1997, 15. 147-149

[3] Waterhouse, R.: 'Small microstrip patch antenna' , Electron. Lett. ,1995,31, pp. 604-605

[4] Wang, Y.J., Lee, C.K., koh, W.J.: 'single-patch and single-layer square microstrip antenna with $67.5 \%$ bandwidth', 'IEEE Trans.Antenna Propag., 2001, 148, pp. 418-422

[5] Quevedo-Treuel, O., Pucci,E.,Rajo-Iglessias, E.: ‘Compact loaded PIFA for multifrequency application' . IEEE Trans. Antennas Propag., 2010, 58, pp. 656-664

[6] Schaubert, D.H.D., Pozar, M., Adrian, A.: 'Effect of microstrip antenna substrate thickness and permittivity: comparison of theories and experiment’. IEEE Trans. Antenna Propag.,1989,AP-37, pp. 677-682

[7] Yang F., Zhang, X.X., Ye, X.N., Rahmat-Samaii, Y.: 'Wide-band E-shaped patch antennas for wireless communications', IEEE Trans Antennas Propag., 2001, 49, pp.1094-1100

[8] Ge, Y., Esselle, K.P ., Bird, T.S.: 'E-shaped patch antennas for high- speed wireless networks', IEEE Trans. Antennas Propag., 2004,52,pp. 3213-3219

[9] Tong. K.F., Luk, K.M., Lee K.F., Lee. R.Q.: ‘ A broad-band U-slot rectangular patch antenna on a microwave substrate’, IEEE Trans Antennas Propag., 2000,48, pp. 954-960

[10] Matin, M.A., Sharif. B.S.,Tsimenidis. C.C.: 'Probe fed stacked patch antenna for wideband applications'. IEEE Trans Antennas Propag., 2007,55,pp 2285-2388

[11] Guo. Y.X., Mak, C.L., Luk. K.M., Lee. K.F.: ‘Analysis and design of L-probe proximity fed-patch antennas’. IEEE Trans. Antenna Propag. .2001.49.pp. 145-149

[12] Kuo, J.S., Wong. K.L.: ‘A low-cost microstrip-line-fed shorted patch antenna for a PCS base station' , Microw. Opt. Technol. Lett.,2001,29,pp 146-147

[13] Guha, D., Antar, Y.M.M.: 'Circular microstrip patch loaded with balanced shorting pins for improved bandwidth', IEEE Antennas Wirel. Propag. Lett., 2006,5,pp. 217-219

[14] Xiong, J.,Ying, Z., He.S.: ‘A broadband low profile patch antenna of compact size with three resonances'. IEEE Trans. Antennas Propag., 2009,57,pp.1838-1843

[15] Peng, L., Ruan, C.L., Wu, X.H.: 'Design and operation of dual/triple-band asymmetric M-shaped microstrip patch antennas'. IEEE Antennas Wirel. Propag. Lett., 2010,9,pp. 1069-1072

[16] Peng, L., Ruan C.L., Zhang, Y.: ‘A novel compact broadband microstrip antenna’ . Proc. APMC, 2007.pp.1-4

[17] Chiu. C.Y., Shum, K.M., Chan, C.H., Luk., K.M.: 'Bandwidth enhancement technique for quarter - wave patch antennas'. IEEE Antenas Wirel. Proapag. Lett,2003,2,pp.130-132

[18] Chiu, C.Y., Chan, C.H., Luk, K.M.: 'Study of small wideband patch antenna with double shorting walls'. IEEE Wirel. Propag. Lett.2004,3,pp.230-231

[19] Chiu, C.Y., Wong, H., Chan. C.H.: 'Study of small wideband folded-patch-feed antennas', IET Microw. Antennas Propag.,2007,1,(2),pp.501-505

[20] Naser-Moghadasi, M., Dadgarpour, A., Jolani,F., Virdee, B.S.: 'Ultra wideband patch antenna with a novel folded-patch technique'. IET Microw. Antennas Propag.,2009,3,(1),pp.164-170 